\title{
Delineation of Subsurface Structures Using Gravity Data of the Shallow Offshore, Lamu Basin, Kenya
}

\author{
Dennis Ombati $\mathbb{D}^{1},{ }^{1}$ John Githiri, ${ }^{1}$ Maurice K'Orowe, ${ }^{1}$ and Erick Nyakundi ${ }^{2}$ \\ ${ }^{1}$ Department of Physics, Jomo Kenyatta University of Agriculture and Technology, P.O. Box 62000-00200, Nairobi, Kenya \\ ${ }^{2}$ Department of Physics, Kisii University, P.O. Box 408-40200, Kisii, Kenya \\ Correspondence should be addressed to Dennis Ombati; dombatius@gmail.com
}

Received 6 May 2021; Revised 14 November 2021; Accepted 29 December 2021; Published 27 January 2022

Academic Editor: Salvatore Gambino

Copyright (c) 2022 Dennis Ombati et al. This is an open access article distributed under the Creative Commons Attribution License, which permits unrestricted use, distribution, and reproduction in any medium, provided the original work is properly cited.

\begin{abstract}
Lamu Basin is located in South Eastern Kenya and covers about $170000 \mathrm{~km}^{2}$ both onshore and offshore. Kenya's Lamu Basin is hitherto underexplored even though there have been notable oil and gas discoveries along the margin of East Africa. This study focuses on the shallow section of the Lamu offshore bounded by $39^{\circ} \mathrm{E}$ to $43^{\circ} \mathrm{E}$ by $2^{\circ} \mathrm{S}$ to $6^{\circ} \mathrm{S}$, whereby, unfortunately, some of the wildcat wells turned out to be dry although expensive. Gravity interpretation techniques such as spectral analysis and first horizontal derivative were applied to the reduced gravity data to delineate and model structures to minimize the high investment risks. The gravity data used in this study were sourced from the International Gravity Bureau (BGI) and National Oil Corporation of Kenya (NOCK) digital data courtesy of companies like Woodside Energy, Anadarko Kenya Limited, and Total Exploration and Production companies. The obtained reduced gravity data were gridded to produce the gravity anomaly grids (Free air, Bouguer, and Isostacy), which were consequently drawn into maps. From spectral analysis, depths to shallow sources and deep sources were estimated. These depths were used to set regional and residual separation filters using the Gaussian filter. The first horizontal derivative (FHD) applied to the regional Isostatic gravity anomaly map yielded features that were inferred as intrasediment fractures/faults trending in NW-SE and NE-SW directions. The features like the ridges, troughs, and faults mainly trending in the NW-SE direction are discernable from the regional anomaly map. The developed models show the basement highs and lows with a possibility of anticlinal and synclinal structures and thick sedimentary successions likely to represent good hydrocarbon source kitchens.
\end{abstract}

\section{Introduction}

Forming part of the passive continental margin of Kenya, South-Eastern Kenya's Lamu Basin covers both onshore and offshore. It relates to the rifted continents like Australia, America, India, Antarctica, Africa, and Madagascar during the Jurassic rifting [1]. East Africa's potential for hydrocarbons is signified by the significant oil and gas discoveries in Mozambique and Tanzania and the heavy oil deposits in Madagascar's conjugate margin [2]. Covering both the onshore and offshore, the basin extends to an area of about $170000 \mathrm{~km}^{2}$ with a $3 \mathrm{~km}$ to $13 \mathrm{~km}$ sediment thickness range for onshore and offshore, respectively [3].
The geology of Lamu Basin is tectonically controlled. These tectonic activities brought about the splitting of Gondwana during the Jurassic and the Anza Rift Cretaceous activity. The Lamu Basin belongs to a passive continental margin classification and is unusual in that it lies in a transitional position between a rifted margin to the North in Somalia and a transform margin to the south. Carbonates, shales, and marine sandstones constitute the sediments of the area (Figure 1(a)) [4]. The Lamu Basin has potential source rocks (ranging from type III to type IV kerogen), Lamu reefs (being potential reservoir targets in near-shore and offshore), and thick and abundant shale sequences within the basin (providing adequate sealing potential). Characteristic traps are mainly faulted 
blocks in the north and anticlinal structures with associated antithetic faults in the south [3].

Even though Lamu offshore basin lies in a similar environment as Tanzania, Mozambique, and Mascarene basins, several wells drilled turned out dry, and the bay has been underexplored [2]. Therefore, the risk necessitates gravity interpretation techniques such as spectral analysis and first horizontal derivative to be applied to the reduced gravity data to delineate and model structures to minimize the high investment risks. The gravity method is paramount in impossible or difficult situations where the seismic process cannot apply [5]. Therefore, gravity complements seismic interpretation.

In estimating the gravity sources' depths and locations for the density contrast contacts, the Shimabara Peninsula, located in southwestern Japan, was studied using integrated interpretation techniques (analytic signal, HGM, and Euler deconvolution) on gravity data [6]. Another study in western India offshore conducted a comparison between shipborne gravity maps and maps derived from satellite gravity for validation purposes. The known elements of geology were positively correlated with the gravity field from the spectral analysis of the gravity data [7]. A study integrating gravity data with interpreted lineaments from remotely sensed images and the geological fault was conducted to understand the geological structure of the Aynak-Logar Valley (ALV) and its surrounding area in eastern Afghanistan [8]. In the study of the Al-Ain region, Abu Dhabi Emirate, United Arab Emirates, subsurface structures were mapped out using corrected gravity data subjected to gravity gradient derivative methods (horizontal gradient, analytic signal, and tilt angle) to enhance the visibility of subsurface geological features [9]. In delineating the subsurface structures and reservoir geometry of the Aluto-Langano geothermal field, Ethiopia, gravity data was interpreted. A regional-residual separation highlights the structures of interest in the calderic system, whereby dominant high Bouguer anomalies underlying Aluto caldera associated with the presence of basaltic rocks and the occurrence of fumarolic activity were identified [10].

Figures 1(b) and 1(c) show the Lamu offshore basin. Figure 1(b) indicates the deep and shallow offshore areas. The red outline shows the study area. Figure $1(\mathrm{c})$ is an overlay of the Isostatic anomaly map on the study area showing some of the wells and seismic lines used later in the study in constraining the modelling.

\section{Gravity Method}

Despite being masked by seismology, the gravity method has remained a crucial constraint in some exploration areas. In hydrocarbon exploration, it was the first geophysical technique applicable in targets below high-velocity zones, regions of salt, underexplored basins, and overthrust and foothill belts [11].

The gravity method determines the subsurface spatial distribution of rock density which causes small changes in the earth's gravitational field strength [12]. The underutilization of gravity as one of the potential field data methods in hydrocarbon exploration is due to the deadline pressure (where exploration companies want quick results and therefore choose a single method such as seismic) whereby explorers decide to give only seismic results. However, it is paramount to use the geophysical gravity method in more complex areas and those covered by basaltic rocks since the seismic method has limited use [5].

The gravity method is preferred in hydrocarbon exploration because it shows both the stratigraphic and structural features. In this method, the subsurface geology is examined based on the variation of rock density giving rise to different earth's gravitational fields. The conceptual idea is that the body that brings about the varying gravity of the earth is a unit of rock whose density is relatively different from other rocks in the vicinity. This body, whose density is different from the rest, possesses an additional mass that results in a perturbed gravity region commonly known as a gravity anomaly [13].

As far as gravity data is concerned, a geological anomaly is any lateral change occurring in the subsurface geology of the area. The lateral change can happen due to either change in density of a horizontal layer or a difference in the horizontality of a constant-density layer. In either case, such a geological anomaly would create the corresponding disturbance in the gravity field, known as the gravity anomaly. Regional gravity anomaly describes large-scale geological changes and residual anomalies when the changes are localized. Due to imminent ambiguity in gravity interpretation and an anomalous body producing a nonunique gravity anomaly, it is paramount to apply constraints to increase solution certainty. The amplitude of the anomaly is the function of both the density difference (density contrast) and the depth of the responsible geological structure [14].

\section{Methodology}

The data used in this study were sourced from the International Gravity Bureau (BGI) and National Oil Corporation of Kenya (NOCK) digital data courtesy of companies like Woodside Energy, Anadarko Kenya Limited, and Total Exploration and Production companies. Correction of gravity results was necessary before interpretation to eliminate variations not resulting from density contrasts of the rocks. The correction is described as reducing gravity data. Gravity reduction was achieved through Eötvös correction, drift correction, elevation corrections (Free air, Bouguer, and Terrain), latitude correction, and tidal correction [15].

The global relief model (ETOP01) and the geopotential model (EGM2008) were applied in reducing the data. Included in the geopotential model (EGM2008) are measurements from satellite gravimetry (GRACE mission), satellite altimetry, and surface gravity (from land, marine, or airborne surveys). The topography and bathymetry data (elevation data) used is from the global relief model (ETOP01) ([16, 17]. The computation of all the gravity anomaly grids and maps was done at the atmosphere's lower limit (earth's surface) with a resolution of $1^{\prime} \times 1^{\prime}$. The Bouguer and Isostatic anomaly maps' reference density is the standard $2670 \mathrm{~kg} / \mathrm{m}^{3}$ [18], which is generally assumed for the density of the included mass in regional gravity surveys [19]. The spherical harmonic gravity coefficients for the 


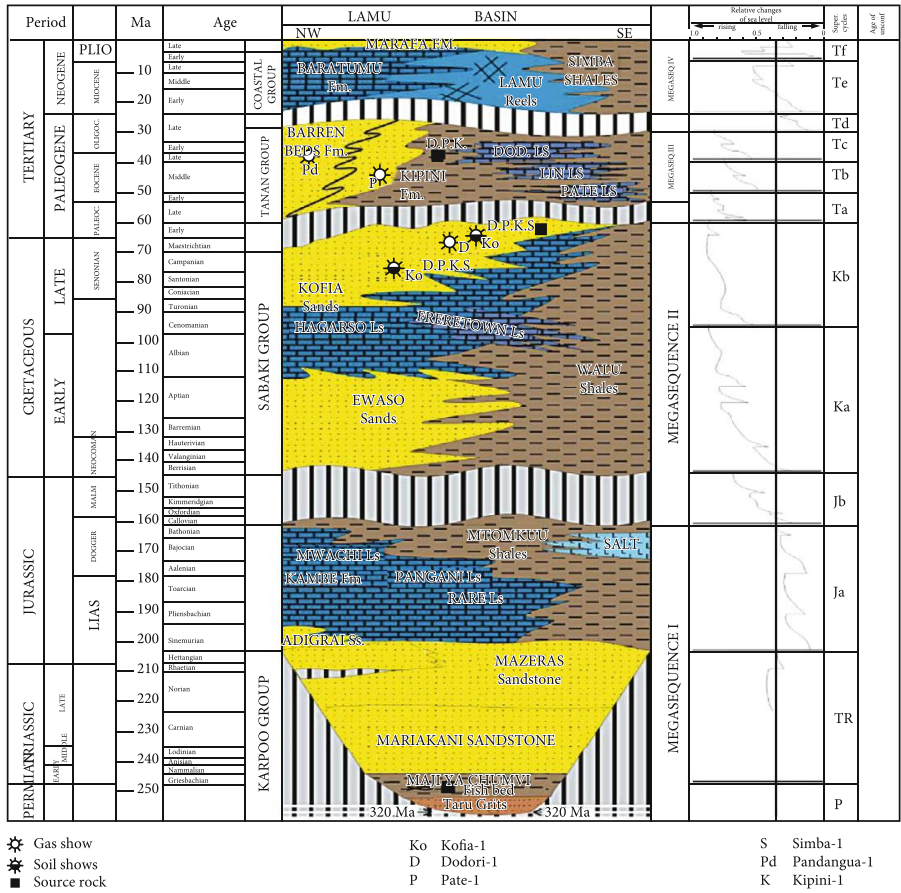

(a)

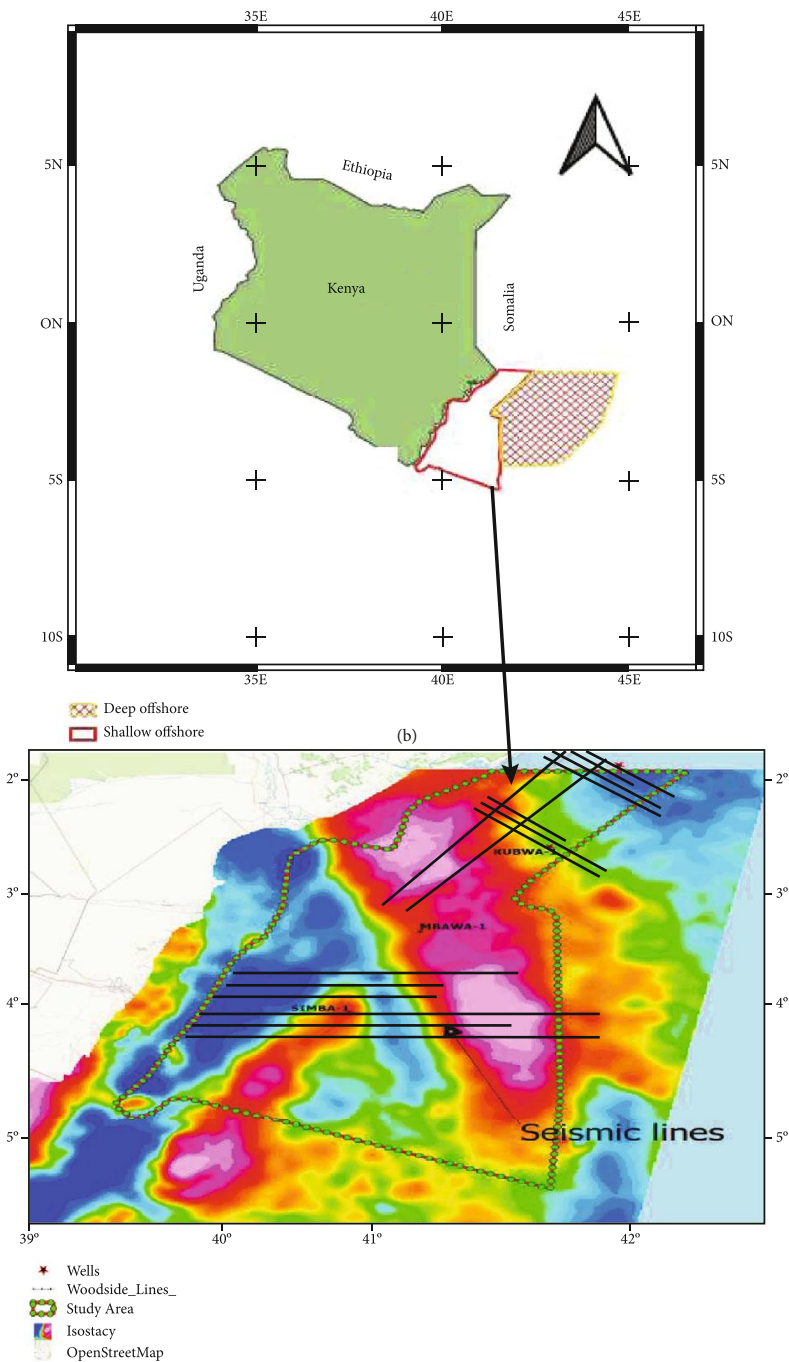

(c)

Figure 1: (a) Stratigraphic section divided into four significant sequences based on the geological and geophysical well data and outcrop studies ranging from Triassic through to Tertiary age [4]. (b, c) Map of Kenya showing the area of study outlined in red (b) and red/ green circles in (c). Source: (b) National Oil Corporation of Kenya (NOCK) Library and (c) an overlay of Isostatic gravity anomaly map, seismic lines, some drilled wells, and area of study.

compensation of all relief components for the AiryHeiskanen Isostatic model with a constant compensation depth $T_{c}=30 \mathrm{~km}$ were applied [16].

In the analysis of gravity data, spectral analysis, first horizontal derivative (FHD), and modelling were employed. The power spectrum method was used for depth estimation and for designing filters to separate regional and residual fields (or deeper from shallower sources) [20]. The Isostatic gravity anomaly map was then subjected to spectral analysis to guide the residualization process. This resulted in a residual map and a regional map showing residual and regional features, respectively. The first horizontal derivative (FHD) was applied to the regional Isostatic gravity anomaly to enhance and clarify the structure edges. The first horizontal derivative is the value of gravity anomaly changing horizontally [21]. Modelling yielded cross-sections with four layers (upper sediments, lower sediments, old deposits, and the basement layer) to a maximum depth of about fifteen kilometers.

\section{Results and Discussions}

The anomaly maps show regions of gravity highs (positive) and lows (negative) as shown in Figures 2(a)-2(c).

Figure 2(a) is the increase in gravity as you move from onshore to offshore. This regional effect reflects the impact of the denser oceanic crust relative to the continental crust. Here, the bathymetry sourced anomalies have been removed but not Moho-sourced anomalies ([22, 23] (IGC footnotes). Because of the effect of thick continental crust and thin oceanic crust, the gravity anomalies show negative and positive gravity signatures, respectively [5].

Similarly, from Figure 2(a), the Bouguer gravity anomaly map indicates that towards the land area are low amplitude 


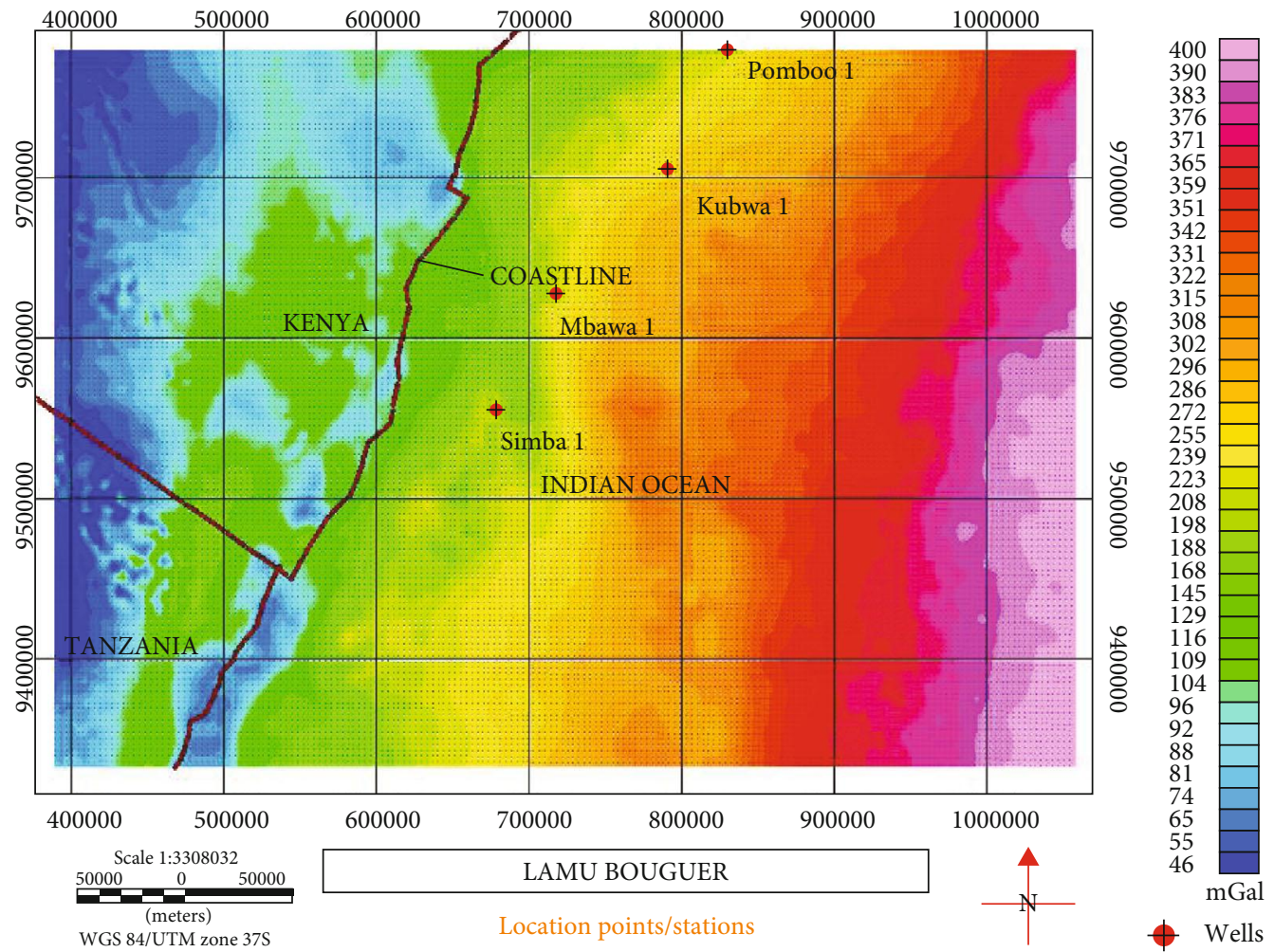

(a)

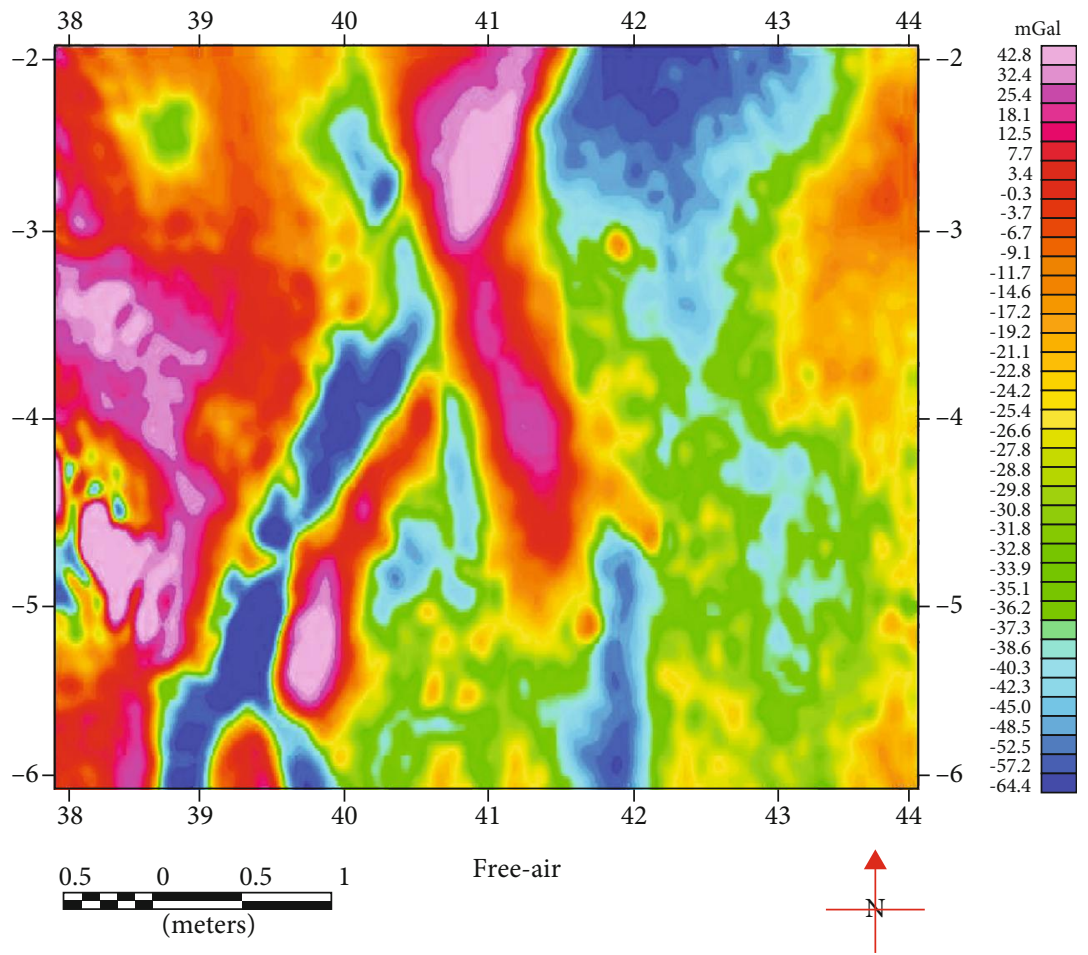

(b)

Figure 2: Continued. 


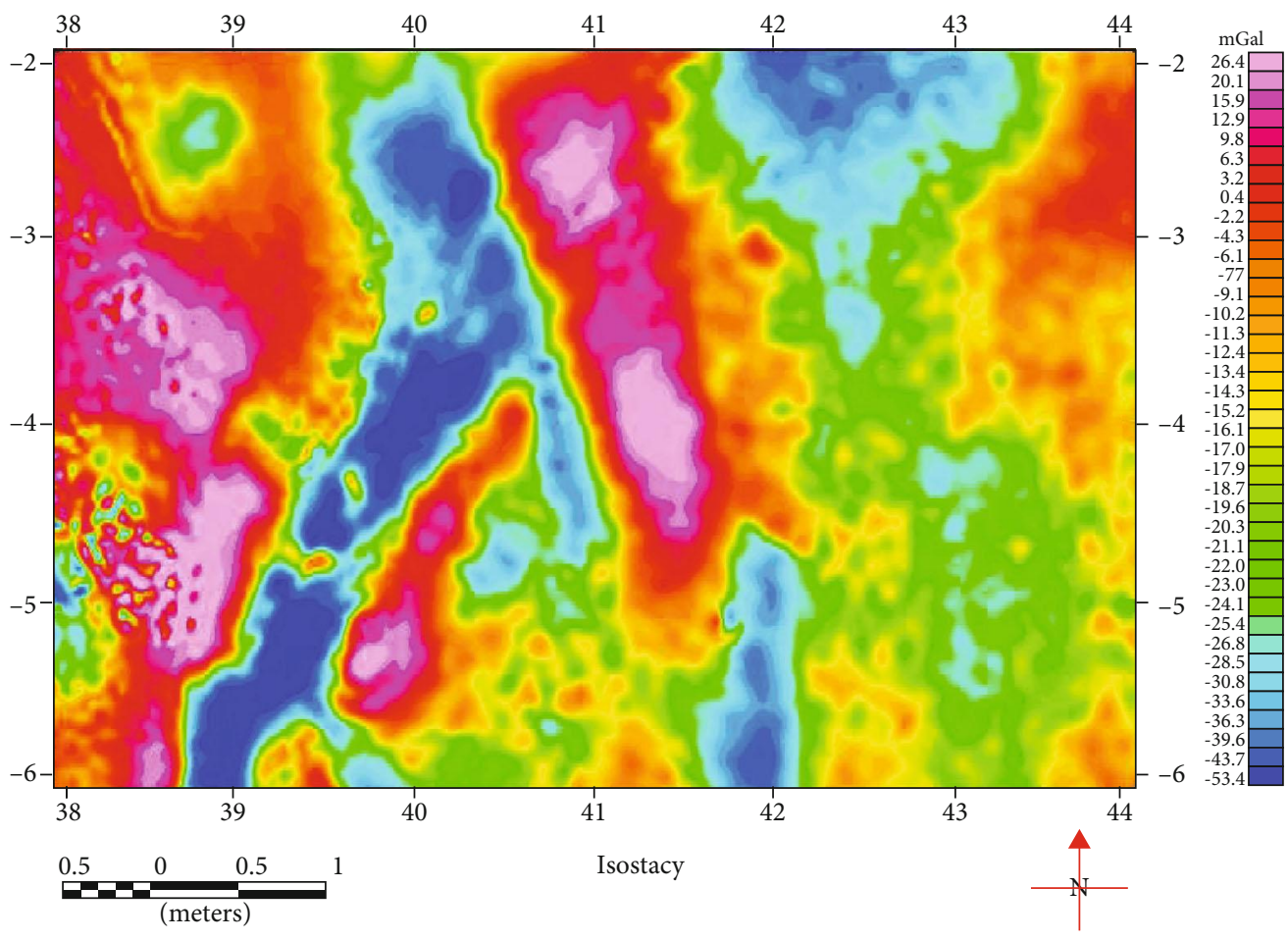

(c)

Figure 2: (a) The Bouguer anomaly map shows the coastline, drilled wells, and stations; (b) The free-air anomaly map shows the ridges and troughs; (c) Isostacy anomaly map shows the gravity highs and lows.

(negative) gravity anomalies while high amplitude (positive) gravity anomalies are seen to be dominating towards the deep sea [24]. There is a high amplitude gravity anomaly as one goes eastwardly with great gravity value increasing trend in the same direction ranging from about $45.4 \mathrm{mGals}$ to about $399.9 \mathrm{mGals}$.

Figure 2(b) represents the gravity observed data after being subjected to free air correction. This correction reduces the effects of elevation differences between measuring points. It can be noticed from Figure 2(b) that there is a variation of gravity anomaly amplitude across the study area, with the central part of the figure showing potential features. N-S separates the gravity lows and highs between 390E and 430E and NE-SW trending sharp density contrast lineaments. These can be inferred to be significant fracture zones or faults. The range of the gravity values within the study area is $-64.4 \mathrm{mGals}$ to $42.8 \mathrm{mGals}$. The change in gravity due to elevation change is rated by $0.3086 \mathrm{mGals} / \mathrm{meter}$. Thus, to reduce the change in gravity to sea level, a gravity value measured at elevation (h) meter must be done by increasing the observed gravity by $0.3086 \mathrm{~h}$ mGals [14].

Figure 2(c) represents data devoid of water effects and the masking or distortion of the anomalies by the Moho effect. Isostatic anomalies provide the most significant value for interpretation since it accounts for most of the impact that may affect the measured gravity data. The gravity values from the Isostatic anomaly map range between $-53.4 \mathrm{mGals}$ and $26.4 \mathrm{mGals}$. The Isostatic anomaly map was then subjected to spectral analysis, which was then used to estimate the depth to be shallow and deep sources, as shown in Figure 3. These depths were used to set filters for regional (Figure 4) and residual (Figure 5(b)) separation using the Gaussian filter. First, the horizontal derivative (FHD) was applied to the regional Isostatic anomaly map, which yielded features that were inferred as intrasediment fractures/faults trending in NW-SE and NE-SW directions (Figure 5(c)). Discernable from the regional map, are features like the ridges, troughs, and faults mainly trending in the NW-SE direction. Selected profiles, cutting across the Isostatic anomaly map through ridges, troughs, faults, and drilled wells and along some seismic lines, were used to develop models.

\section{Spectral Analysis}

In regions of limited crustal structure information, the power spectral analysis technique can yield potential density contrast depths in the crust. The power spectral decay curve shape is affected by the factors of the source ensemble like the thickness, widths, and depths. The distinguishing feature of the logarithmic decay of the energy curve shows the rapid decrease of the curve at low wavenumbers (deep sources) and a gentler decline of the remainder of the curve (shallow sources).

A typical energy spectrum may consist of three parts, namely, a deep source component, a shallow source component, and a noise component. The depth to the source ensemble $H(\widehat{h}, q)$ is the main factor that controls the shape 


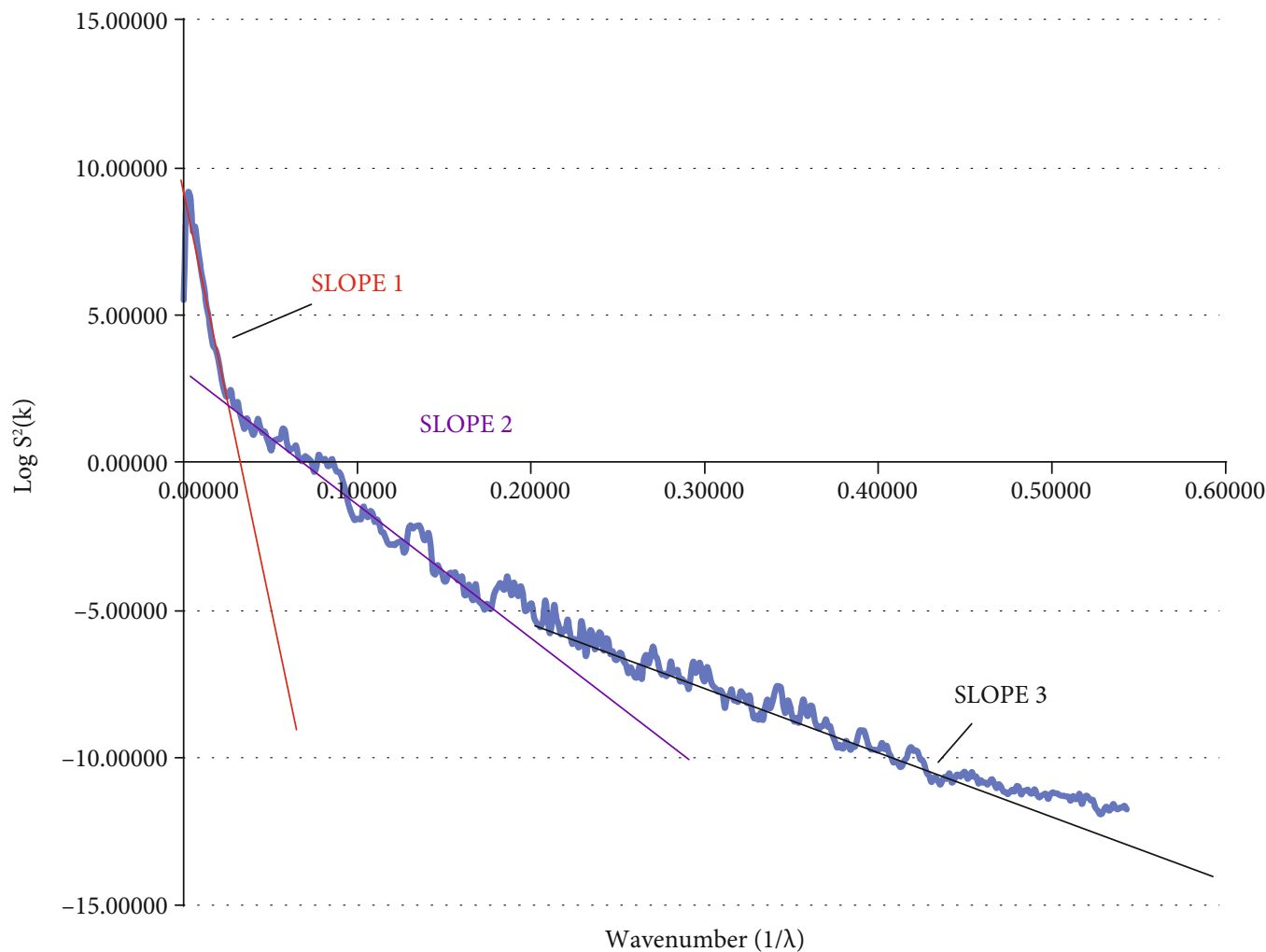

FIgURE 3: This plot illustrates the typical reduction in energy with increasing wavenumber.

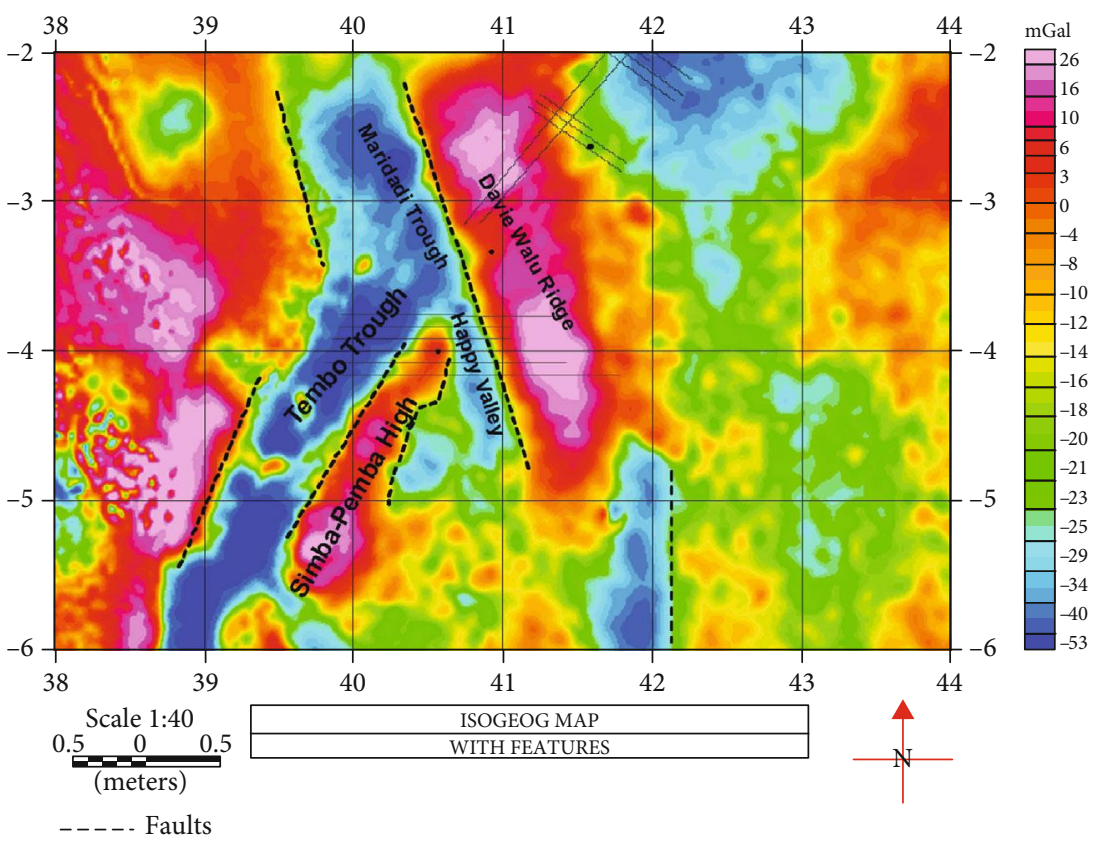

FIgURE 4: Regional map with the main features indicated and labelled.

of the energy spectral decay curve, as is expressed in

$$
H(\widehat{\mathrm{h}}, q)=e^{-2 \mathrm{~h} \wedge q}
$$

The decay slopes of the power spectral curve describe the various depths of a source ensemble. The deep source ensemble is described at a lower frequency (low wavenumber) and the shallow source ensemble at a higher frequency (high wavenumber). The depth of a source ensemble can 


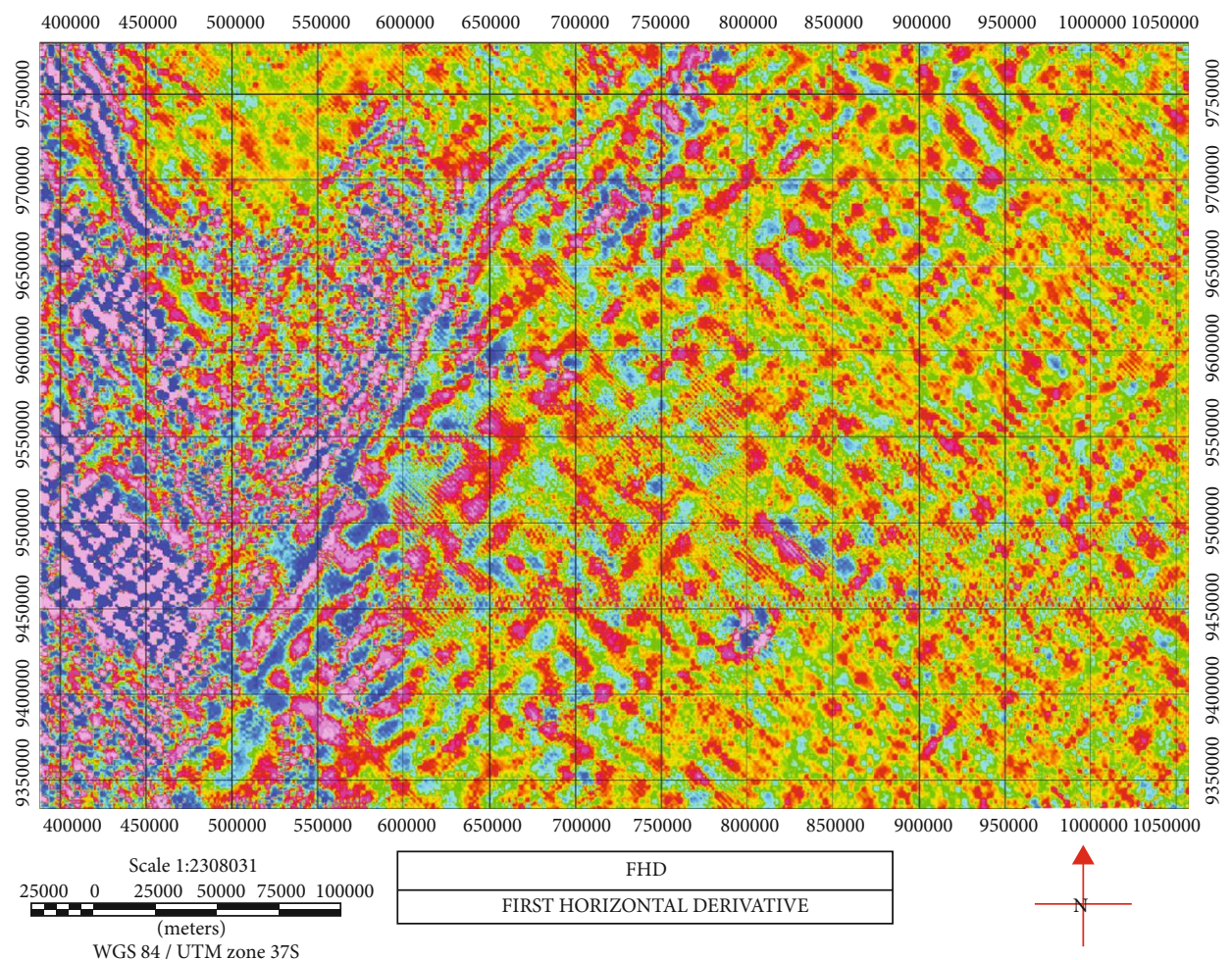

(a)

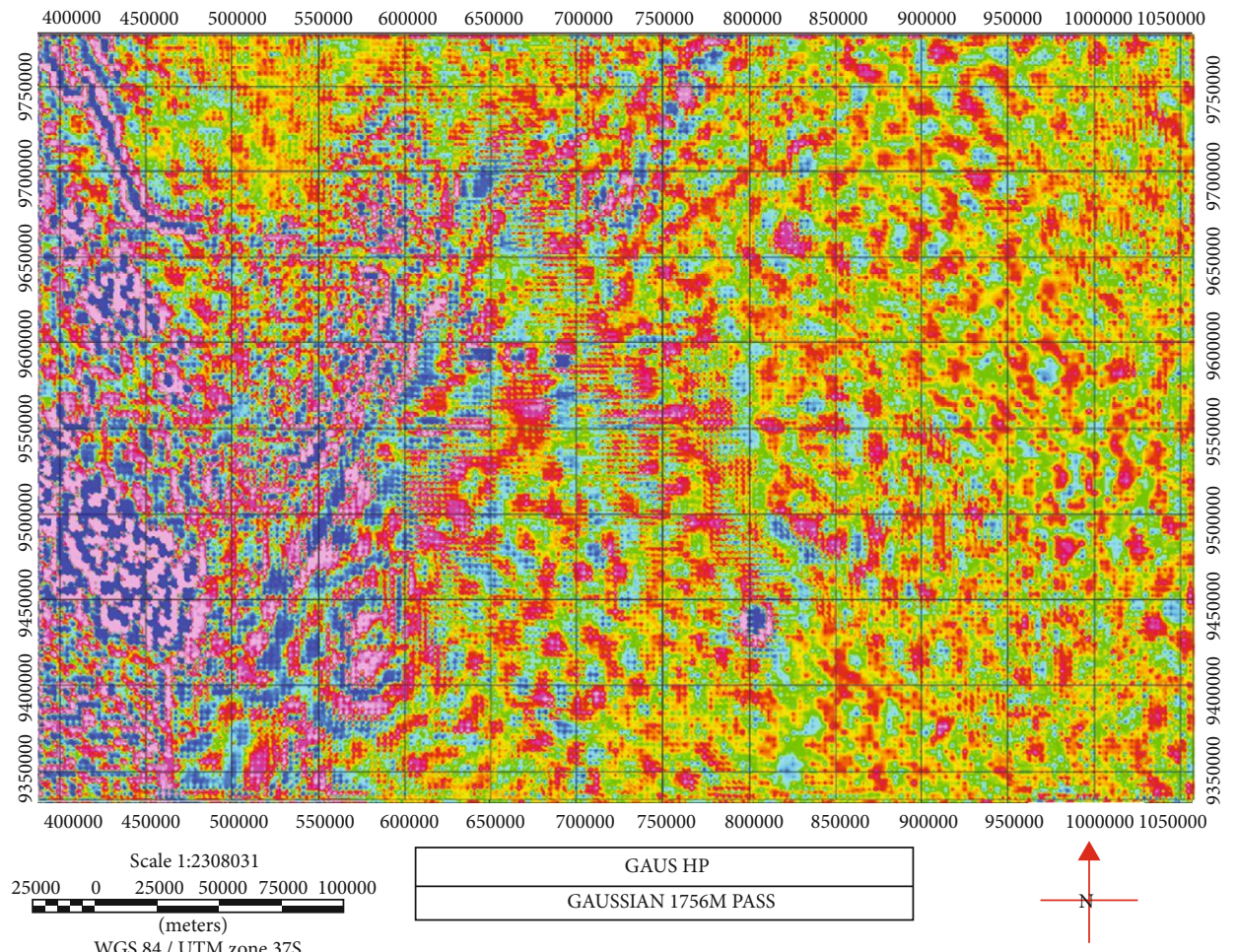

(b)

Figure 5: Continued. 


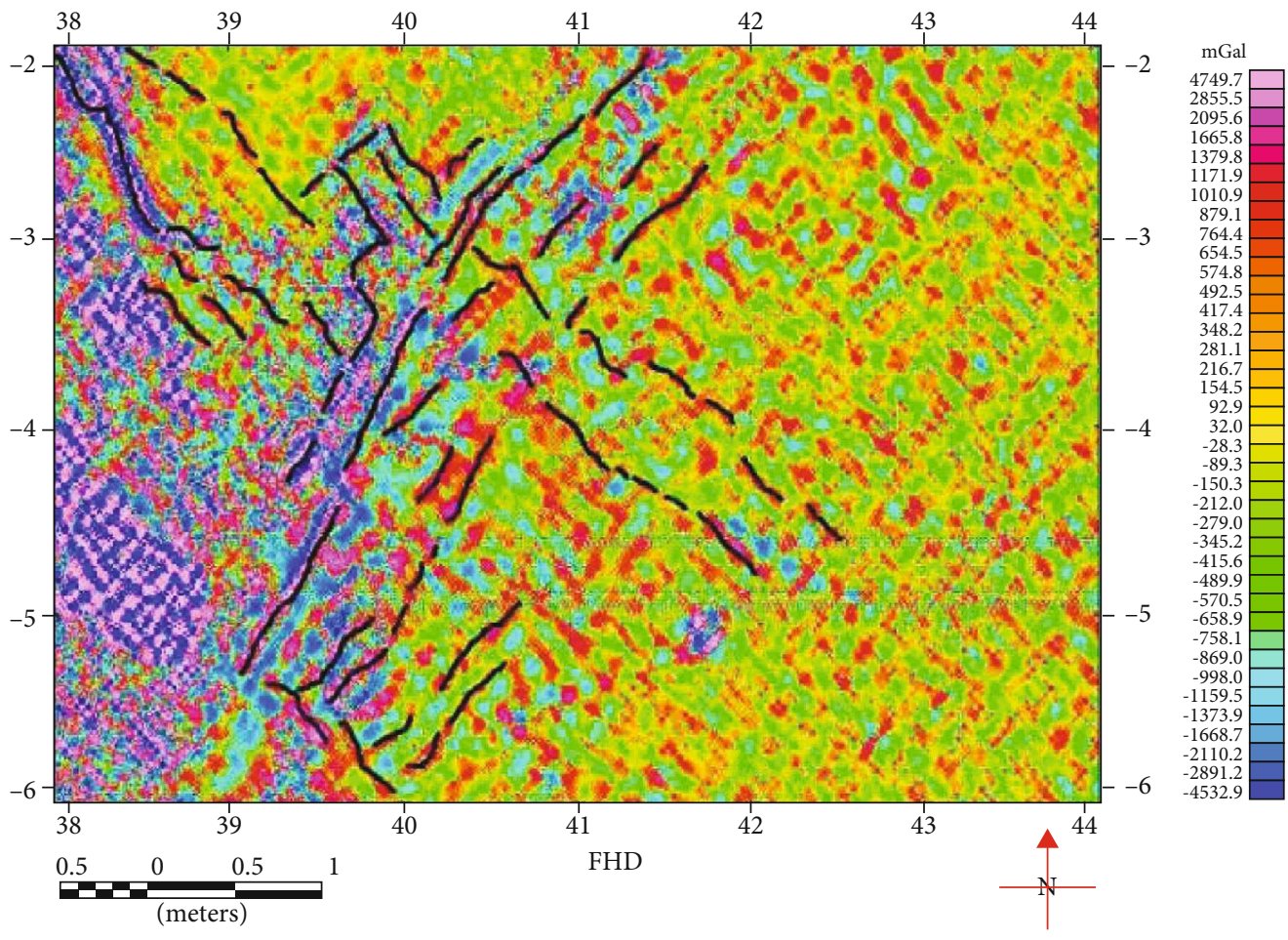

(c)

Figure 5: (a) Shows the first horizontal derivative. (b) Shows the Gaussian high pass filter at the shallow depth of $1756 \mathrm{~m}$. (c) First horizontal derivative with highlighted faults.

be computed from the slope of a tangent fitted to any linear segment of the curve [6].

The power spectrum method is used for depth estimation and designing filters to separate regional and residual fields (or deeper from shallower sources) [20]. A plot of $\log$ power versus wavenumber, Figure 3 , gives a straight line whose slope equals $-4 \pi h$ (for $k=1 / \lambda$ ) from

$$
\log S^{2}(k)=\log B-4 \pi h k,
$$

i.e., slope is proportional to depth to source since

$$
h=\frac{s}{4 \pi} .
$$

Figure 3 shows three principal slopes: Slope 1, Slope 2, and Slope 3. Their respective depths are calculated using the formula in equation (3):

$$
h=-\frac{s}{4 \pi} .
$$

Slope 1:

$$
\text { Depth, } h=16820 \mathrm{~m} \text {. }
$$

Slope 2:

$$
\text { Depth, } h=5598 \mathrm{~m} \text {. }
$$

Slope 3:

$$
\text { Depth, } h=1756 \mathrm{~m} \text {. }
$$

Therefore, depth is related to wavenumber but not with a simple relationship where one wavenumber represents one depth [12].

Figure 4(a) is the first horizontal derivative map derived from the root sum square of the horizontal $x$ first derivative and horizontal $y$ first derivative. This filter helps outline areas of sharp contrast in density between vertical blocks. This figure can highlight the potential fracture zones as shown with discontinuous lines in Figure 4(c). The total horizontal derivative or Horizontal Gradient Magnitude (HGM) is commonly used to enhance the anomalous source's boundaries. It is computed using equation (8) [25]:

$$
\mathrm{FHD}=\sqrt{\left(\frac{\partial g}{\partial x}\right)^{2}+\left(\frac{\partial g}{\partial y}\right)^{2}} .
$$

\section{Modelling}

Figures 6(a) and 6(b) are cross-sections of gravity profiles cutting across the significant features, namely, troughs and ridges and passing through wells (Figure 1(c)). These cross-sections were constrained with a $2 \mathrm{D}$ seismic section (Figures $7(\mathrm{a})$ and $7(\mathrm{~b})$ ), stratigraphic information from drilled wells, completion reports like the Pomboo-1 well 

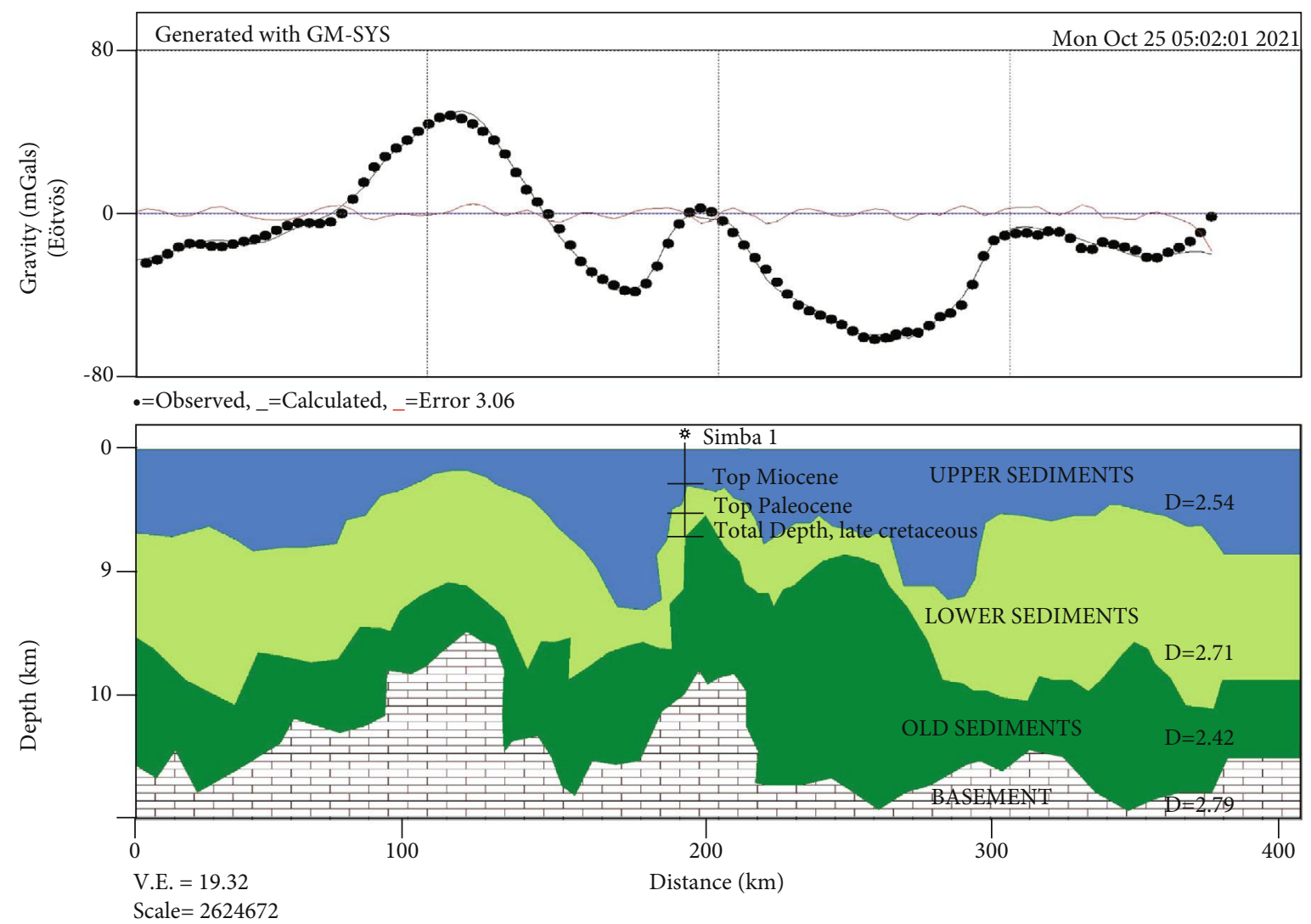

(a)

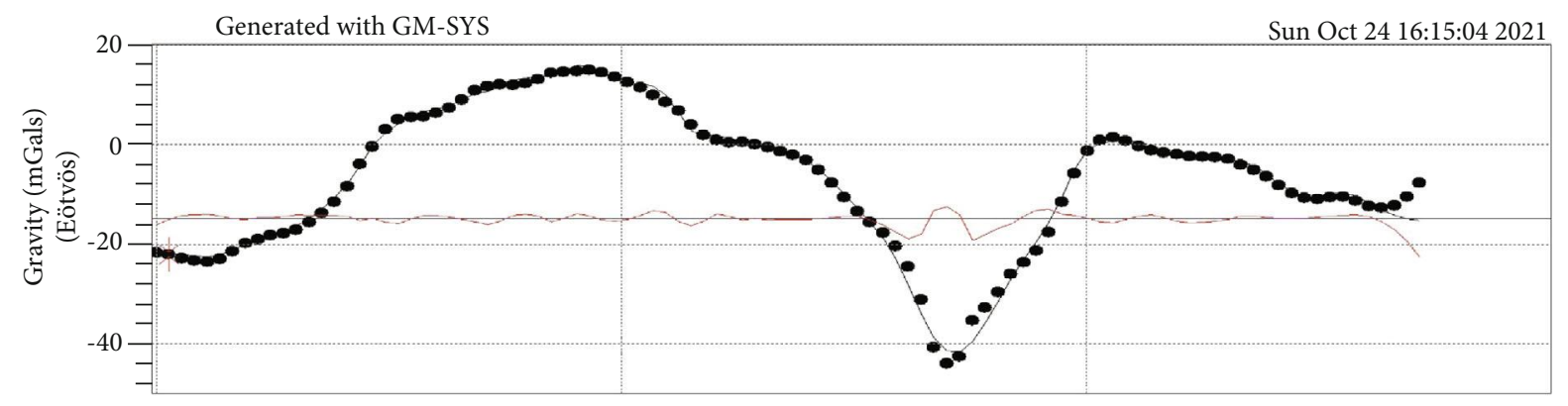

•=Observed,_=Calculated, _=Error 1.407

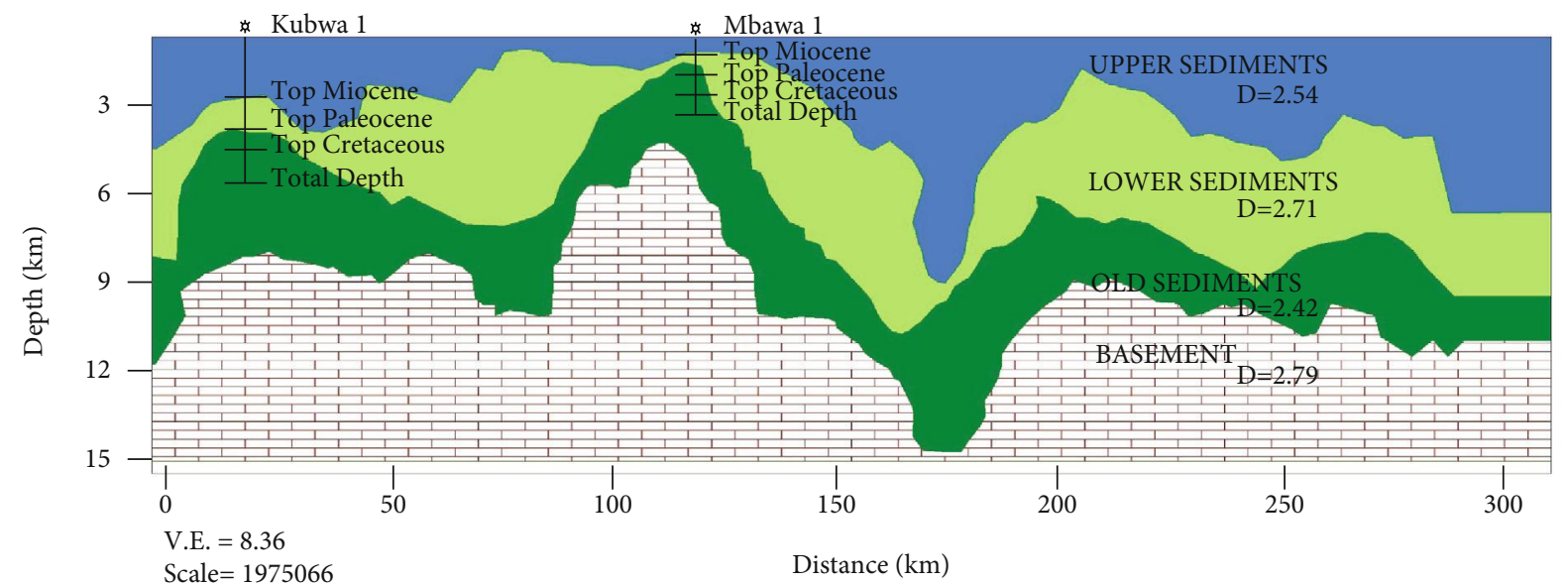

(b)

Figure 6: (a) Model of a profile cutting through Simba-1 well in the EW direction. (b) Model of a profile cutting through Kubwa-1 and Mbawa-1. 


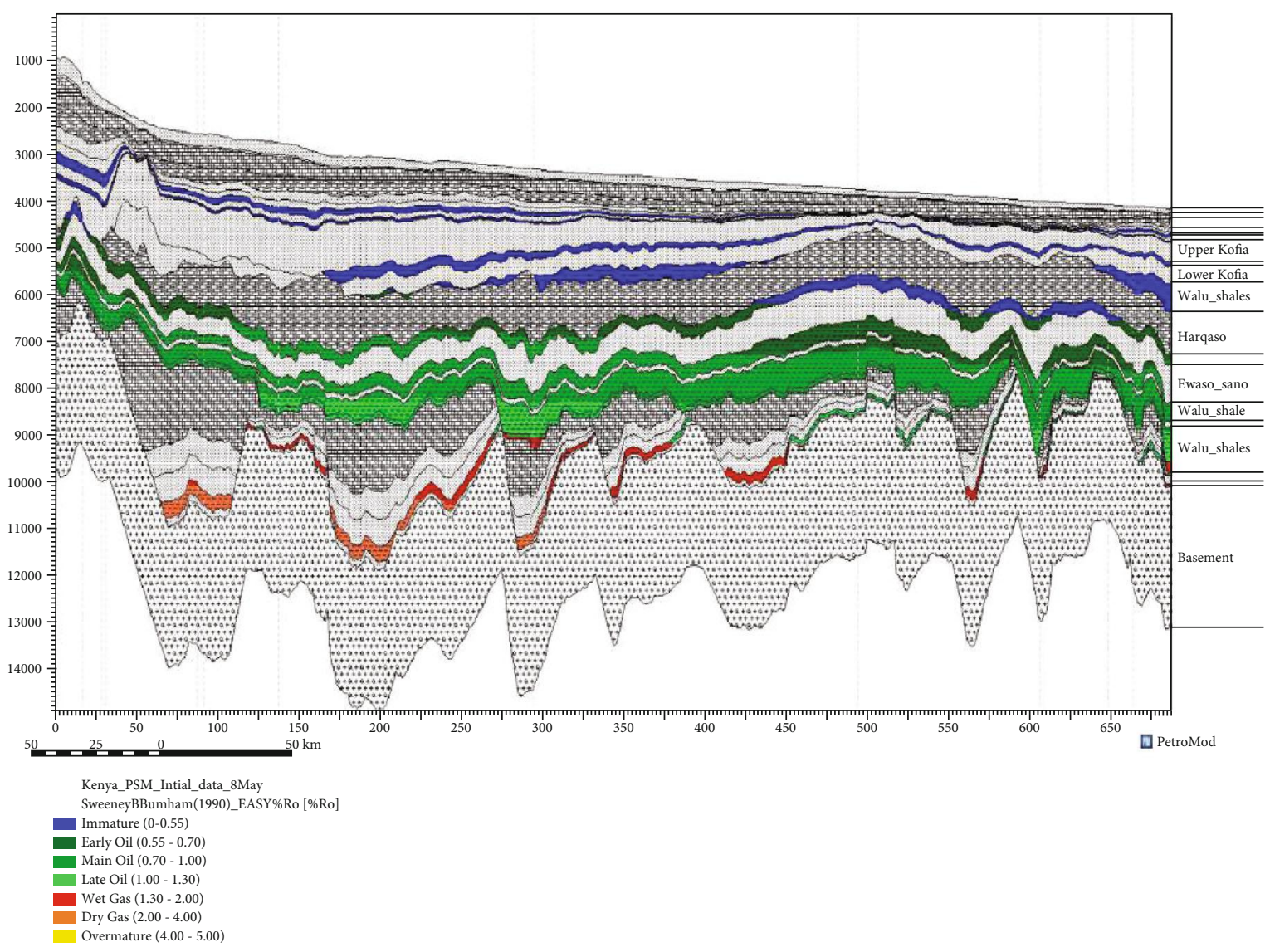

(a)

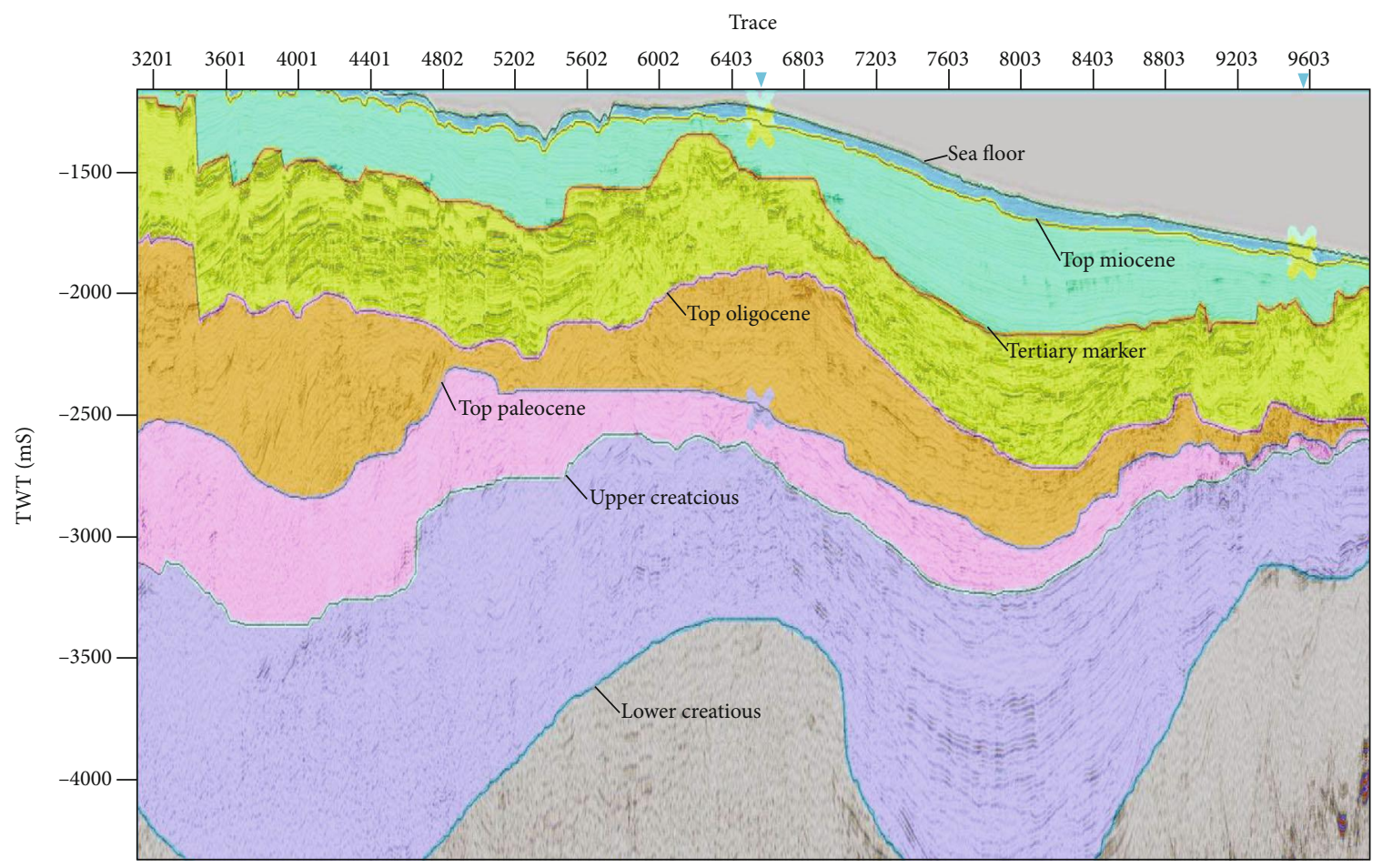

(b)

Figure 7: (a) Shows a 2D seismic section model. Based on the Sweeney and Burnham (1990) scale, the modelled present-day source rock maturity is highlighted by the regional line [2]. (b) Is a 2D seismic section showing Interpreted horizons along line 9 near Mbawa well indicating seven identified horizons as labelled. 
completion report, and published papers like $([4,26-28]$ on the geology of the area.

Figure $7(a)$ is a $2 \mathrm{D}$ seismic section model showing sedimentary layers. The blue layer indicates the immature, green oil, and red gas windows. The most interesting point to note is that within a column of $9 \mathrm{~km}$ from the seabed are strata within which several shale beds were identified. Shales are known oil reservoirs, and the hope for one in the Lamu Basin lies within these rocks. The seismic section in Figure 7(b), which shows the interpreted horizons along a seismic line near Mbawa well, was used to estimate the number of possible layers, while the approximate depth of the deepest point of interest was calculated using the seismic section model, Figure 7(a). These figures represent major stratigraphic sequences separated by unconformities. The sequences were interpreted as being deposited under periods of transgression and regression, driven by a change in the sea level, accommodation space, or both.

The well completion report was used in identifying possible layers and their stratification. The report as well as the said published papers gave great insights concerning the regional and local geology of the study area and therefore constrained the modelling process.

The GM-SYS generated sections go to a maximum depth of fifteen kilometers and show four significant layers: upper sediments, lower sediments, old sediments, and the basement layer. The undulations of the layers forming the basement highs beneath the upper sediments would constitute the best oil reservoir entrapment that would migrate upward following the lines of weakness. The zones of contact between the troughs and the ridge are the most likely candidates for fracture areas that would form possible migration paths. The possibility of having significant oil and gas source kitchens is represented by the said troughs signified by thick sedimentary successions and basement lows.

\section{Conclusion}

Several significant features can be discerned in analyzing the gravity data and exploring their impact on hydrocarbon potential. The gravity models are comparative with the seismic section model and the horizon interpretation seismic section, and both indicate a possibility of anticlinal and synclinal structures, which are suitable subsurface structural leads in hydrocarbon exploration. The application of spectral analysis yielded depths to shallow sources (approx. $1800 \mathrm{~m}$ ) and deep sources (approx. $16800 \mathrm{~m}$ ). These depths were used to set regional and residual separation filters using the Gaussian filter. First, the horizontal derivative applied to the regional Isostatic anomaly yielded features inferred as intrasediment fractures/faults trending in NW-SE and NESW directions. The Davie-Walu ridge is the dominant feature in the data offshore, as evidenced from the regional map. The Pemba-Simba ridge is as well identified to the south. On the sides of the ridges are seen troughs which are identified as Maridadi, Tembo, and Happy valley. The ridges may act as a migration focus for hydrocarbons to migrate up-dip and trapping configuration. The gravity models show that the troughs, the basement lows, and thick sedimentary successions likely represent good hydrocarbon source kitchens.

\section{Recommendation}

This study recommends seismic data reinterpretation constrained with well log information to delineate closed structures and potential subsurface traps.

\section{Data Availability}

The gravity data used to support the findings of this study were supplied by the Bureau Gravimétrique International (BGI) under restriction to transmit it to third parties and hence cannot be made freely available. Requests for access to these data should be made to http://bgi.obs-mip.fr/dataproducts/gravity-databases/marine-gravity-datas/. The well information data and part of the seismic data used were obtained from the National Oil Corporation of Kenya (NOCK) for academic use and restricted from being made public since the block understudy is under licence.

\section{Conflicts of Interest}

The authors declare that they have no conflicts of interest.

\section{Acknowledgments}

Special thanks are due to the International Gravity Bureau (BGI) and National Oil Corporation of Kenya (NOCK) for the gravity, well, and seismic data and related information and their continued support in allowing me to access the software in their work stations.

\section{References}

[1] M. F. Coffin and P. D. Rabinowitz, "Reconstruction of Madagascar and Africa: evidence from the Davie fracture zone and western Somali basin," Journal of Geophysical Research: Solid Earth, vol. 92, no. B9, pp. 9385-9406, 1987.

[2] O. Osicki, O. Schenk, and D. Kornpihl, "Prospectivity and petroleum systems modelling of the offshore Lamu Basin, Kenya: implications for an emerging hydrocarbon province," AAPG Search and Discovery Article, p. 10700, 2015.

[3] NOCK, Hydrocarbon Potential of the Coastal Onshore and Offshore Lamu Basin of Southeast Kenya, NOCK, NAIROBI, 1995.

[4] K. Nyagah, "Stratigraphy, depositional history and environments of deposition of Cretaceous through Tertiary strata in the Lamu Basin, southeast Kenya and implications for reservoirs for hydrocarbon exploration," Sedimentary Geology, vol. 96, no. 1-2, pp. 43-71, 1995.

[5] W. Lowrie and A. Fichtner, Fundamentals of Geophysics, Cambridge university press, 2020.

[6] H. Saibi, J. Nishijima, S. Ehara, and E. Aboud, "Integrated gradient interpretation techniques for $2 \mathrm{D}$ and $3 \mathrm{D}$ gravity data interpretation," Earth, Planets and Space, vol. 58, no. 7, pp. 815-821, 2006.

[7] R. Bhattacharyya, P. Verma, and T. Majumdar, "High-Resolution Satellite Geoids/Gravity Over the Western Indian 
Offshore for Tectonics and Hydrocarbon Exploration," Journal of Marine Sciences, vol. 38, no. 1, pp. 116-125, 2009.

[8] M. Azizi and H. Saibi, "Integrating gravity data with remotely sensed data for structural investigation of the Aynak-Logar Valley, eastern Afghanistan, and the surrounding area," IEEE Journal of Selected Topics in Applied Earth Observations and Remote Sensing, vol. 8, no. 2, pp. 816-824, 2015.

[9] H. Saibi, A. Gabr, and F. S. Mohamed, "Subsurface structural mapping using gravity data of Al-Ain region, Abu Dhabi Emirate, United Arab Emirates," Geophysical Journal International, vol. 216, no. 2, pp. 1201-1213, 2019.

[10] B. D. Mulugeta, Y. Fujimitsu, J. Nishijima, and H. Saibi, "Interpretation of gravity data to delineate the subsurface structures and reservoir geometry of the Aluto-Langano geothermal field, Ethiopia," Geothermics, vol. 94, article 102093, 2021.

[11] M. N. Nabighian, M. E. Ander, V. J. S. Grauch et al., "Historical development of the gravity method in exploration," Geophysics, vol. 70, no. 6, p. 63ND-89ND, 2005.

[12] J. D. Fairhead, Advances in Gravity and Magnetic Processing and Interpretation, EAGE Publications, 2016.

[13] A. B. Watts, Isostasy and Flexure of the Lithosphere, Cambridge University Press, 2001.

[14] H. N. Alsadi and E. N. Baban, Gravity Exploration Method, Academia, 2014.

[15] A. Murray and R. Tracey, Best Practices in Gravity Surveying: GeoscienceAustralia, 2001, http://www.ga.gov.au/webtemp/ image_cache/GA13068.pdf.

[16] G. Balmino, N. Vales, S. Bonvalot, and A. Briais, "Spherical harmonic modelling to ultra-high degree of Bouguer and isostatic anomalies," Journal of Geodesy, vol. 86, no. 7, pp. 499520, 2012.

[17] S. Bonvalot, G. Balmino, A. Briais et al., "World gravity map," in Bureau Gravimetrique International (BGI), Map, CGMWBGI-CNES728, IRD, Paris, 2012.

[18] F. Caratori, F. Graziano, L. Cocchi, C. Carmisciano, and P. Stefanelli, "Determining the optimal Bouguer density for a gravity data set: implications for the isostatic setting of the Mediterranean Sea," Geophysical Journal International, vol. 169, no. 2, pp. 380-388, 2007.

[19] W. J. Hinze, "Bouguer reduction density, why 2.67?," Geophysics, vol. 68, no. 5, pp. 1559-1560, 2003.

[20] A. Spector and F. Grant, "Statistical models for interpreting aeromagnetic data," Geophysics, vol. 35, no. 2, pp. 293-302, 1970.

[21] M. S. Rosid and H. Siregar, "Determining fault structure using first horizontal derivative (FHD) and horizontal, vertical, diagonal maxima (HVDM) method: a comparative study," in Paper presented at the AIP Conference Proceedings, AIP Publishing LLC, vol. 1862, Las vegas, NV, USA, 2017.

[22] D. Close, "Isostasy and gravity modelling: integrating potential field data in interpretation workflows," Official Publication of the Canadians Society of Exploration Geophysicists (CSEG RECORDER), vol. 35, no. 6, 2010.

[23] C. M. Green, J. D. Fairhead, and S. Maus, "Satellite-derived gravity: where we are and what's next," The Leading Edge, vol. 17, no. 1, pp. 77-79, 1998.

[24] Y. L. Ekinci and E. Yiğitbaş, "Interpretation of gravity anomalies to delineate some structural features of Biga and Gelibolu peninsulas and their surroundings (north-west Turkey)," Geodinamica Acta, vol. 27, no. 4, pp. 300-319, 2015.
[25] R. J. Blakely, Potential Theory in Gravity and Magnetic Applications, Cambridge university press, 2009.

[26] A. Bosellini, "East Africa continental margins," Geology, vol. 14, no. 1, pp. 76-78, 1986.

[27] F. Cruciani and M. R. Barchi, "The Lamu Basin deepwater fold-and-thrust belt: an example of a margin-scale, gravitydriven thrust belt along the continental passive margin of East Africa," Tectonics, vol. 35, no. 3, pp. 491-510, 2016.

[28] A. Masinde, Petroleum Prospectivity of Offshore Lamu Basin, Davie Walu Fracture Zone, Kenya, 2019. 